\title{
The Development of Cyber Counseling as a Counseling Service Model for High School Students in the Digital Age
}

\author{
I Ketut Gading ${ }^{1^{*}}$ \\ 1Department of Education, Psychology and Guidance. Universitas Pendidikan Ganesha, Singaraja, Indonesia \\ e-mail: iketutgading@undiksha.ac.id
}

\begin{abstract}
This research aimed at developing theoretical models and guidelines for cyber counseling, as well as examining their acceptability and effectiveness. The stages of the study consisted of $4 D$ namely define, design, develop, and disseminate. The acceptance test involved 2 experts as reviewers, while the effectiveness test involved 30 high school students as participants. The effectiveness of models and guidelines was measured by participants' responses to the benefits of cyber counseling. Data were collected using questionnaires and then analyzed using a t-test. Results showed that the theoretical model of cyber counseling consisted of raw input, instrumental input, environmental input, process, and counseling goals. The guidelines for cyber counseling were set out in the steps of cyber counseling consisting of initial communication, internalization, and termination. The acceptance of the model and cyber counseling guidelines was very high with a coefficient of 1.00. Therefore, cyber counseling should be used as a model of counseling services for high school students in the digital age effectively.
\end{abstract}

Keywords: Cyber Counseling; Counseling Service Model; Digital Age

\section{Introduction}

Advances in communication science and technology had a significant impact on changing habits of communication between people, especially long-distance communication. When the internet was not existing, humans communicated remotely using letters, telegrams, or landlines. After the internet was innovated, long-distance communication between humans occurred through the internet with various applications, and the communication was far more efficient and more effective. Therefore, it was not surprising that internet users were growing so rapidly throughout the world. Geraijasa (2019) reported that the number of internet users worldwide from 2005 to 2015 experienced continuous growth. In 2005, internet users around the world were 1 billion, then in 2015 internet users increased to 3.5 billion. Chaffey (2020) mentioned that since January 2020, 4.54 billion people around the world use the internet. Meanwhile, the Asean-Indonesia National Secretariat (2019), based on research conducted by Google and Temasek, revealed that in 2018 internet users in the Southeast Asia region were 350 million people and predicted to be 7.5 billion by 2030 . Indonesia citizens itself was the 6 th most internet user in the world (Setti \& Wanto, 2019). In the coming years, internet users will certainly continue to increase both in terms of intensity and users. Fields of life that use the internet as a medium of communication will also increase until at one point all areas of life need the internet as a medium of communication.

The use of the internet as a medium of information and communication has become a common requirement in various fields, including education and guidance and counseling (Wilson et al., 2017). Sutijono \& Farid (2018) stated that the challenge of counselors in the era of globalization was to provide acceptable services to the millennial generation, who had a different mindset, values, and behaviors because of the development of smartphones, the

\footnotetext{
* Corresponding author.

Received 15 May 2020; Accepted 13 June 2020; Available online 20 June 2020

(C) 2020 JPI. All Rights Reserved
} 
internet, and the social media. The millennial generation was a generation that was very technologically literate and very familiar with social media, thus counselors must adjust themself (Prasetya et al. 2020).

Counseling services carried out in the field often experienced obstacles that made the counseling process did not achieve the expected goals. Garde et al. (2017), Simone et al. (2013), and Maili et al. (2020) explained that the counselee tended to be reluctant to independently visit the counselor when facing a problematic situation because the relative distance of the counselor's place and the lack of time to visit the counselor. Rida (2019) added that in the school, counselors also faced lacked sufficient time to do face-to-face counseling at school. There were only a few school counselors to serve all the students thus it took a lot of time to solve all problems. Dowling \& Rickwood (2016) strengthened that the counselee experienced anxiety during the face-to-face counseling process. Li,Lau et al. (2013); Dowling \& Rickwood (2016); Maili et al. (2020) emphasized that counselees need a new counseling model that was more time-saving, not tied to the place, and more practical to meet the needs of students in the current era where access to services and information through technology has advanced and expanded.

A new counseling service model is needed in the form of cyber counseling to serve counselees in the era of rapidly developing information and communication technology. Cyber counseling allows counselors to serve counselees with more time-saving, independent of place, and more practical because it can be done anywhere and anytime without meeting in person (Maili et al., 2020; Richards, 2009). In addition, cyber counseling not only facilitates counselees to express their sensitive issues but also increases access to counseling services for people who live in remote areas, people with disabilities, people who are too shy for face-to-face counseling, busy people with limited time, and people who are worried about being stigmatized as problematic persons ( $\mathrm{Li}$, Lau et al., 2013; Mishna et al., 2015; Prasetiawan, 2016).

Cyber counseling, or e-therapy, as defined by the National Board for Certified Counselors, is a professional counseling practice and the delivery of information that occurred when clients and counselors were in separate or remote locations and utilized electronic media in the form of the internet to communicate (Mishna et al., 2015; Norizan \& Hashim, 2013). Meanwhile, Li, Lau et al. (2013); Bastemur \& Bastemur (2015); Savic et al. (2018) referred cyber counseling to online counseling because it used the internet as a communication channel. Meanwhile, according to Sari (2015), cyber counseling was one of the guidance and counseling strategies that were virtual or counseling that took place through the help of an internet connection in the form of websites, e-mails, facebook, video conferences (yahoo messenger), etc. Lan (2016) pointed out that cyber counseling was a new method to help people deal with adversity. Based on those opinions, it can be concluded that cyber counseling is counseling conducted between counselor and counselee to help counselees develop themselves and solve problems experienced by utilizing internet connection as a medium for counseling. The internet connection can be in the form of a website, email, facebook, blog, whatsapp, line, twitter, teleconference, and other forms of internet applications.

Some research on cyber counseling has been done previously. Mishna et al. (2015) examined the advantages of cyber counseling and found that cyber counseling had the following advantages compared to face-to-face counseling: (1) ease of accessibility if the counselee experiences problems there was no need to go outside the house or go far to see a counselor; (2) cyber counseling, especially in writing, allowed the counselee to re-read the counseling conversation later on when the counselee experienced the same problem as; (3) 
cyber counseling could avoid conveying emotions, a kind of emotional transference from counselee to counselor; (4) cyber counseling allowed counselees to be more willing to express comfortably personal things that were very difficult to convey in person. Then the research conducted by Attridge (2011), Murphy et al. (2009), and Péñate (2012) examined the effectiveness of cyber counseling or online therapy and found that cyber counseling or online therapy was generally as effective and satisfying as face-to-face counseling. Mallen et al., (2005) studied the feasibility of cyber counseling by reviewing the various counseling psychology literature and suggested that online counseling could be a viable service choice for some clients, especially those who were isolated. Richards \& Viganó (2013) emphasized that to date online counseling had the same positive impact as face-to-face counseling and was able to replicate the facilitation of face-to-face counseling conditions. It was stated that strong proofs were needed to build confidence that cyber counseling had better effectiveness, unique media, and facilitative nature. Prasetiawan (2016) found that cyber counseling with the help of facebook could reduce the tendency to play online games.

The above studies studied the superiority and effectiveness of cyber counseling to help counselees developed themselves and overcame the problems experienced. None of these studies tried to develop a model of cyber counseling and tested it empirically thus it could be used as a reference in carrying out cyber counseling. Therefore, this study aimed at developing a prototype model of cyber counseling and analyzing the acceptance and effectiveness of the cyber counseling model empirically.

According to Salleh et al. (2011), there were five main categories of cyber counseling (CC), namely: (1) process, (2) skills, (3) approaches, (4) ethics, and (5) limitations of cyber counseling. Each category had its stages. Meanwhile, as an educational service model, one prototype of the cyber counseling model could refer to the education model as a system (Joyce et al., 2000). In which case, the cyber counseling model consists of raw input, instrumental input, environmental input, process, and output.

\section{Methods}

This development research was conducted for 8 months in 2017 by adopting the 4D model (define, design, develop, and disseminate). The first four months were considered as the define and design phase. In this phase, several things were completed, namely: (a) designed prototype model and prepared the concept of cyber counseling guidelines, (b) assessed the suitability of the model and the concept of cyber counseling guidelines through focus group discussions, and (d) validated and refined cyber counseling models and guidelines. The next two months were the development phase. In this phase, the effectiveness of the model and guidelines were tested limitedly through experimental research. The last two months were the disseminate phase. During this phase, the cyber counseling model and guidebooks were improved through broader dissemination activities collaborated with guidance and counseling teachers.

This research was carried out at Universitas Pendidikan Ganesha (Undiksha) and the Laboratory High School of Universitas Pendidikan Ganesha. In the define and design phase, the model was reviewed by two experts from Undiksha and 3 guidance and counseling teachers from Laboratory High School. In the development stage, the research was carried out at the Laboratory High School, with the subjects of 10 randomly selected students from class XI. While in the disseminating phase, the research was conducted at the Laboratory High School with 30 randomly selected students.

The data required in this study were student responses regarding the level of satisfaction with cyber counseling as a model of high school student counseling services. 
The level of counseling satisfaction measured using the questionnaire included satisfaction with the counseling process and satisfaction with the results of counseling. Satisfaction with the counseling process included easy access to counseling, smooth counseling process, and confidentiality of the counseling process. While satisfaction with the results concerned the benefits obtained by the counselee in establishing himself and helping to solve the problems experienced. The questionnaire was developed in the form of a Likert model of satisfaction measurement counseling scale with an interval scale of 1 to 4 . The questionnaire consisted of 20 items with 10 items being favorable and 10 other items being unfavorable. Each item was accompanied by 4 alternative responses consisting of very dissatisfied with a score of 1 , dissatisfied with a score of 2 , satisfied with a score of 3 , and very satisfied with a score of 4 . Before being used in research, the questionnaire had been tested for content validity by two experts in guidance and counseling, and one expert in learning technology. The results of the questionnaire content validity test lead to a coefficient of content validity $(\mathrm{CV})$ of 1.00 , thus the questionnaire contents were considered valid (Gregory, 2012).

This research used various data sources. For the acceptance test, the data source was an expert in guidance and counseling, an expert in educational technology, and three teachers in guidance and counseling at the Laboratory High School. For the limited effectiveness test, the data source was 10 students in class XI of the Laboratory High School, while the data source for the wider effectiveness test was 30 students of the Laboratory High School. Data analysis in this research was carried out in two stages. The first stage tested the acceptability of the cyber counseling model and guidelines, and the second stage analyzed the effectiveness of the model and cyber counseling guidelines.

The acceptance test of the model and the guidance of cyber counseling was performed using expert test and was analyzed using the Inter-rater agreement technique (Gregory, 2012). Whereas the effectiveness test of the model and the guidance of cyber counseling were analyzed using the t-test by comparing the actual number of students' responses regarding the benefits of cyber counseling to the ideal responses. If the calculated mean number ( $\left.M_{\text {count }}\right)$ was significantly higher than the ideal mean number $\left(M_{4}\right)$ at a significance level of $\leq 0.05$, then the cyber counseling model and guidelines were considered effective and feasible to use.

\section{Results and Discussion}

\subsection{Cyber Counseling Theoretical Model}

Based on the observations and the results of focus group discussions involving experts in guidance and counseling, an expert in information technology, and three teachers in guidance and counseling towards counseling in general, against cyber counseling in particular, and the learning model as an analogy, the theoretical model of cyber counseling consists of elements of purpose, process elements, and input elements (input). The input element consists of raw input, instrumental input, and environmental input (Fig. 1).

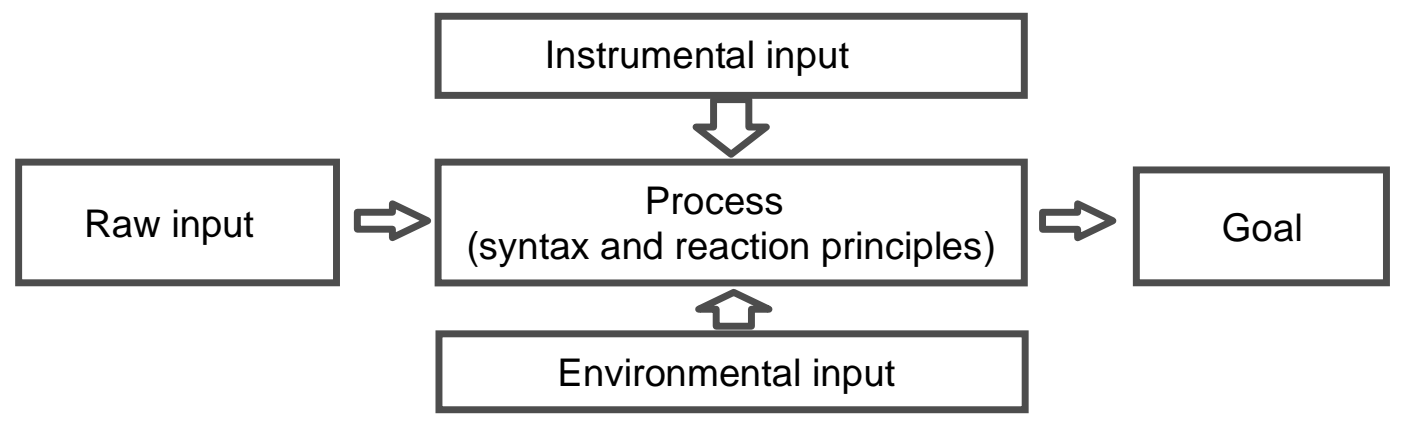


Figure 1. Cyber Counseling Model

Each element can be explained as follows. The purpose of cyber counseling is to help counselees develop themselves and solve their problems. Raw input cyber counseling is individuals who are not yet independent and face problems in their lives. Instrumental input elements in cyber counseling consist of a counselor, computer, or mobile phone with email, facebook, google meet, zoom, and whatsapp applications. Environmental input in cyber counseling includes guarantees of confidentiality, an atmosphere of openness, parental support, teacher support, and peer support. The process elements of the cyber counseling consist of syntax or counseling steps and the principle of reaction or the way the counselor treats the counselee. Syntax or steps of cyber counseling consists of the initial communication stage, the internalization stage, and the termination stage. And the principle of reaction or how counselors treat counselees in cyber counseling can be direct or indirect.

\subsection{Cyber Counseling Guidelines}

\section{a. Pengertian Cyber Counseling}

Cyber counseling is counseling conducted between counselor and counselee to help counselees develop themselves and solve problems experienced by utilizing an internet connection as a counseling medium. The internet connection can be in the form of a website, e-mail, facebook, blog, whatsapp, line that uses written and telephone communication, video call, or videoconference using verbal communication media.

\section{b. The Stages of Cyber Counseling}

The steps in cyber counseling are: (1) the initial communication phase, which includes initial reading followed by advanced reading and relationship building; structuring to help clients understand cyber counseling which includes procedures, sessions, and time limits; guidelines for emergencies; and limitations of cyber counseling. Some of them are communicated on the site while others are communicated by the counselor after initial communication. (2) The internalization stage, which is the stage where there is serious involvement in establishing therapeutic relationships through texts where the counselor and client focus on the text and develop trust through the text. (3) The ending stage, in which the client expresses his appreciation for the counselor's response or service followed by a plan of action. The counselor and client agree that the problems experienced by the client have been resolved and there will be no more email in the counseling process. The stages of the counseling relationship evolve from initial introductions to relationship formation followed by forming work alliances (work agreements), with a focus on problems experienced by clients and their solution, which are similar to traditional counseling processes (Ivey et al., 2012).

\subsection{The Benefits of Cyber Counseling}

Mishna et al. (2015) revealed the advantages of cyber counseling compared to face-toface counseling, as follows: (1) ease of accessibility thus counselees did not need to go outside the house or to go far to see a counselor. When the counselee had a problem, he could immediately contact the counselor to resolve the problem being experienced. (2) With cyber counseling, especially in writing, the counselee could re-read the counseling conversation later on when the counselee experienced the same problem, which was impossible to do if counseling was done in person. (3) Cyber counseling could prevent the counselor from conveying emotions, i.e. the transfer of emotions from the counselee to the 
counselor. For instance, in face-to-face counseling, a counselee who had certain feelings such as anger or hatred toward objects in the past, those feelings could be transferred to the counselor unconsciously. This emotional transfer could reduce the professionalism of the counseling process. (4) Cyber counseling allowed counselees to express personal things conveniently that might be difficult to convey if counseling was done in person.

\subsection{The Weaknesses of Cyber Counseling}

Some weaknesses of cyber counseling are: (1) very dependent on the internet connection, if the counselor or counselee does not have an internet connection then the counseling cannot be done, (2) physical contact to provide reinforcement, such as tapping on the shoulder and shaking hands, cannot be done, (3) confidentiality of counseling is not fully guaranteed because online counseling can be tapped.

\subsection{The Acceptability of Model and Guidelines of Cyber Counseling}

Acceptability which included utility, feasibility, and accuracy of the model and cyber counseling guidelines were tested by experts. All experts were asked to assess the acceptability of the model and cyber counseling guidelines through a questionnaire consisting of 18 items. Alternative expert responses consisted of 1 (highly irrelevant), 2 (irrelevant), 3 (relevant), and 4 (very relevant). The four alternative responses of experts were then grouped into 2 namely: responses 1 and 2 were categorized as irrelevant, while responses 3 and 4 were categorized as relevant. The responses of the two experts were entered into a $2 \times 2$ cross-tabulation and analyzed with the formula: content validity $(C V)=A$ / $A+(A+C+D)$, with $A$ was a column that contained the number of items that were declared relevant both by expert 1 and expert 2 . $B$ and $C$ were columns that contained the number of items that were responded differently between the two experts, and $D$ was the column that contained the number of items that were responded to not relevant by both experts.

The results of the acceptance test of the cyber counseling model showed that the two experts agreed that all questionnaire items were relevant, thus CV $=18 / 18+0+0+0=$ 1.00. Therefore, it could be concluded that the acceptance of the cyber counseling model was categorized as high $(>0.80)$. Accordingly, the results of the cyber counseling guidelines test also showed that both experts agreed that all items of the questionnaire acceptance of the cyber counseling guidelines are relevant, thus $C V=18 / 18+0+0+0=1.00$. Therefore, it could be concluded that the acceptance of cyber counseling guidelines was also high $(>0.80)$.

\subsection{The Effectiveness of Cyber Counseling Model}

Table 1. Counseling Satisfaction Score on the Process and Results of Counseling

\begin{tabular}{|c|c|c|c|}
\hline No & Participant Code & Cycle I Score & Cycle II Score \\
\hline 1 & 10.1 & 54 & 66 \\
\hline 2 & 10.2 & 44 & 64 \\
\hline 3 & 10.3 & 50 & 60 \\
\hline 4 & 10.4 & 50 & 60 \\
\hline 5 & 10.5 & 58 & 68 \\
\hline 6 & 10.6 & 53 & 64 \\
\hline 7 & 10.7 & 54 & 65 \\
\hline
\end{tabular}




\begin{tabular}{|c|c|c|c|}
\hline No & Participant Code & Cycle I Score & Cycle II Score \\
\hline 8 & 10.8 & 55 & 61 \\
\hline 9 & 10.9 & 51 & 60 \\
\hline 10 & 10.1 & 48 & 60 \\
\hline 11 & 11.1 & 44 & 60 \\
\hline 12 & 11.2 & 52 & 60 \\
\hline 13 & 11.3 & 50 & 61 \\
\hline 14 & 11.4 & 51 & 66 \\
\hline 15 & 11.5 & 56 & 62 \\
\hline 16 & 11.6 & 52 & 60 \\
\hline 17 & 11.7 & 50 & 62 \\
\hline 18 & 11.8 & 46 & 62 \\
\hline 19 & 11.9 & 52 & 64 \\
\hline 20 & 11.1 & 54 & 64 \\
\hline 21 & 12.1 & 64 & 66 \\
\hline 22 & 12.2 & 56 & 60 \\
\hline 23 & 12.3 & 60 & 63 \\
\hline 24 & 12.4 & 53 & 64 \\
\hline 25 & 12.5 & 64 & 64 \\
\hline 26 & 12.6 & 42 & 63 \\
\hline 27 & 12.7 & 63 & 62 \\
\hline 28 & 12.8 & 62 & 66 \\
\hline 29 & 12.9 & 56 & 60 \\
\hline 30 & 12.1 & 60 & 60 \\
\hline & & & \\
\hline
\end{tabular}

Table 2. Burning t-test Results for The Effectiveness of Cyber Counseling in Cycle I

\begin{tabular}{cccccccc}
\hline Variable & $\mathbf{N}$ & $\overline{\mathbf{X}}$ & $\mathbf{i}$ & $\sum \mathbf{D}^{2}$ & $\sqrt{ } \sum \mathbf{D}^{2} / \mathbf{N}\left(\mathbf{N}^{2} \mathbf{- 1}\right)$ & $\mathbf{t}_{\text {hitung }}$ & $\begin{array}{c}\mathbf{t}_{\text {tabel }}(\mathbf{d f}-\mathbf{2 9} ; \\
\mathbf{S i g}=\mathbf{0 . 0 5})\end{array}$ \\
\hline $\begin{array}{c}\text { Satisfaction with } \\
\text { Cyber Counseling }\end{array}$ & 30 & 53,467 & 50 & 1338 & $0, .273$ & 12.708 & 2.045 \\
\hline \multicolumn{7}{l}{$N=$ no. of respondents; $\bar{X}=$ counted average number; $i=$ ideal average number; $D=X-i$}
\end{tabular}

Table 2 showed that the $t_{\text {count }}$ was 12.708 , while the $t_{\text {table }}$ based on the degree of freedom of 29, and the significance level of 0.05 was 2.045. The coefficient of $t_{\text {count }}$ was higher than $t_{\text {table }}$ indicated that cyber counseling was effective as a counseling service in the digital age. Although in the first cycle cyber counseling has proven to be effective as a counseling service in the digital age, there are still 5 out of 30 participants (16.667\%) who received counseling satisfaction scores below the ideal average. Therefore, the study continued in the second cycle. In the second cycle, besides increasing the intensity of counseling, the effectiveness criteria were also increased from an ideal average score of 50 , to a minimum completeness criterion of $75 \%$ of the ideal maximum score of 60 . Data satisfaction on cyber counseling as a counseling service in the digital era after cycle 2 was presented in Table 1 column 4. T-test result from the effectiveness of cyber counseling in the second cycle was presented in Table 3. It showed that the coefficient of $t_{\text {count }}$ was 22.063 . The $t$ value was greater than $t_{\text {table }}$ based on $\mathrm{df}=29$ and a significance level of 0.05 which 
was 2.045 which indicated that cyber counseling was effective as a counseling service for high school students in the digital age.

Table 3. Burning t-test Results for The Effectiveness of Cyber Counseling in Cycle II

\begin{tabular}{|c|c|c|c|c|c|c|c|}
\hline Variable & $\mathbf{N}$ & $\overline{\mathbf{x}}$ & $\mathbf{i}$ & $\sum \mathrm{D}^{2}$ & $\sqrt{ } \sum \mathbf{D}^{2} / \mathbf{N}\left(\mathbf{N}^{2}-\mathbf{1}\right)$ & $t_{\text {count }}$ & $\begin{array}{c}t_{\text {table }}(\mathrm{df}-29 ; \\
\text { Sig }=0,05)\end{array}$ \\
\hline Satisfaction with & & & & & & & \\
\hline $\begin{array}{c}\text { Cyber } \\
\text { Counseling }\end{array}$ & 30 & 62.567 & 60 & 365 & 0.116 & 22.063 & 2.045 \\
\hline
\end{tabular}

The effectiveness test of the cyber counseling model was carried out in two stages. The first stage was carried out through experimental research involving three guidance and counseling teachers as counselors and ten high school students as counselees selected randomly from class XI. Before counseling, counselors and counselees were trained to conduct online counseling through the internet application whatsapp, email, and videocall. Each counselor handled three to four counselees. Counseling was carried out for four weeks with a frequency of counseling between two to four times a week using the application agreed by the counselor and the counselee. After counseling, the counselees were given a questionnaire to measure the level of satisfaction of counseling services conducted by cyber counseling.

The results of data analysis using the t-test by comparing the actual average number and the ideal average number obtained t value of 15.87. Based on the degree of freedom (df) $\mathrm{N}-1=10-1=9$ and the significance level of 0.05 the value of the rejection limit of the $\mathrm{t}-$ value in the table of $t$ values is 1.833 . This means that the value of $t$ is significant. The significance of the $t$ value implies that there is a significant difference between the actual average number and the ideal average number of student satisfaction with counseling services through cyber counseling. The results of this study prove that cyber counseling is an effective counseling service in the digital age.

In the second stage, the effectiveness of the cyber counseling model was carried out by conducting dissemination through research into guidance and counseling action. This research was conducted with 30 participants from Laboratory High School students who voluntarily agreed to be involved in the research. Each participant consisted of 10 class $X$ students, 10 class XI students, and 10 class XII students. Every 10 students were counseled by a counselor. Counseling was carried out in two cycles, each cycle consisting of the stages of action planning, action implementation, observation or evaluation, and reflection.

In cycle 1 the activities carried out included: (1) in the planning stage, the activities were compiling a counseling plan, strengthening the teacher's guidance and counseling to carry out cyber counseling, training students to use counseling devices, preparing questionnaires to measure student satisfaction with the process and results in counseling; (2) at the implementation stage, counseling was carried out through cyber counseling applications that had been prepared by researchers with the help of an information technology expert. Counseling was carried out for four weeks with a frequency of counseling for each student between 2 to 3 times counseling a week, (3) at the observation or evaluation stage, a questionnaire was distributed to participants to measure the counselee's 
satisfaction with the counseling process and results, and (4) the reflection stage was carried out to assess the results of counseling.

Analysis of the effectiveness of cyber counseling showed that the $t_{\text {count }}$ was higher than the rejection limit of the $t_{\text {table }}$ value $(12.708>2.045)$ which indicated that the $t_{\text {count }}$ value was significant. The significance of the $t$ value pointed out that the actual average counselee satisfaction with cyber counseling services was significantly higher than the ideal average. The result of the analysis implied that cyber counseling was effective as a counseling service in the digital age. However, the actual average number was only slightly higher than the ideal average and did not reach $75 \%$. Moreover, there were still five students who scored below the ideal average (50), and four students scored at the ideal average. These results were not satisfying, especially if the standard was improved not only based on an average ideal number but based on $75 \%$ or $80 \%$ achievement percentage. Therefore, it took a deep reflection on the results of research cycle 1.

The results of interviews with counselors to trace the behavior of counselees who scored below the ideal average revealed that the counselee did not conduct the counseling process intensively, they only had short conversations, and sometimes the counselor did not close the counseling properly. These results encourage researchers to conduct interviews with counselees who score below the ideal average. The results of this interview revealed that the counselee did not feel comfortable with the counselor he got, the counselee felt they lacked the time to do counseling, and the counselee felt it was inappropriate to consult the counselor's problem because the problem was very personal.

Based on the results of the interview, in cycle 2 some improvements were made to the counseling process: (1) the counselee was given the freedom to choose counselors from the three counselors provided, (2) counseling time was scheduled every Monday, Wednesday and Friday after returning from school, (3 ) Before cycle 2 counseling is conducted, all participants are gathered to get an explanation that the counseling process takes place in a very private condition, all conversations are kept confidential, and the counselor also promises to be professional on the counselee's problem. Counselors are asked to promise to be unconditioned positive regard to whatever problems experienced by the counselee; (4) the success parameters are increased from an ideal average of 50 to $75 \%$ of the ideal maximum score (60). With such improvements, cyber counseling is continued in cycle 2 for 4 weeks with a frequency of 3 times a week every Monday, Wednesday, and Friday, and can be added another time according to the agreement between counselor and counselee.

After counseling cycle 2 ends, all counselees are given another questionnaire to measure their satisfaction with the counseling process and results. $T$ test results to test the effectiveness of cyber counseling by comparing the average actual score with an achievement level of $75 \%$ (60) found a tcount of 22.063. Based on df 30 and a significance level of 0.05 , the ttable value of 2.045 was obtained. $T$ value greater than $t$ table indicates that the $t$ value is significant. This indicates that the average counselee's satisfaction with the counseling process and results is significantly higher than the $75 \%$ parameter $(60)$. Thus, it can be concluded that cyber counseling is an effective counseling service for high school students in the digital age.

The results showed that the theoretical model of cyber counseling included: raw input, instrumental input, environmental input, process, and goals. The steps of cyber counseling include (1) initial communication stage, (2) internalization stage, and (3) ending phase. This cyber counseling model refers to the education model as a system and learning model as stated by Joyce et al. (2000). The education model as a system views education as 
consisting of input, process, and output components. The input component consists of raw input, instrumental input, and environmental input. Not much different from this concept, Joyce et al. (2000) suggested that a model (learning) must contain several things, namely: (1) syntax, (2) impact (instructional and accompaniment), (3) reaction principle, (4) social system, and (5) support system

The syntax is the activity stage of a model. The social system is a situation or atmosphere and norms that apply. The principle of reaction is a pattern of activities that illustrates how teachers should see and treat students. Support systems are all the tools, materials, and tools needed to implement the model. The instructional impact is an outcome that is to be achieved directly by directing students to the expected goals. The accompanying impact is another learning outcome produced by a learning process without direct influence by the teacher.

The results of this study also showed that the theoretical model of cyber counseling and the guidelines for implementing cyber counseling had a very high acceptance. This means that all aspects of acceptance are considered relevant by all experts. In addition, effectiveness tests reveal that cyber counseling models and guidelines are effective for high school students in the digital age. Mishna et al. (2015) emphasized that cyber counseling has several advantages when compared to face-to-face counseling. Some of these advantages are (1) ease of accessibility, (2) allowing counselees to re-read counseling conversations in the future, (3) allowing counselees to be more courageous to express comfortably personal matters.

This easy accessibility makes it easier for counselees to contact the counselor when experiencing problems. Murphy et al. (2009) and Bastemur \& Bastemur (2015) assert that online counseling is not bound by distance and time. Even counseling can be done anywhere and anytime according to the needs of the counselee and counselor. With cyber counseling, especially in writing, it allows the counselee to re-read the counseling conversation later on when the counselee experiences the same problem. Related to this, Budianto et al. (2019) added that online counseling can provide opportunities for parents to monitor counselee development. Parents can monitor the results of counseling through the history of conversations conducted through online counseling, so parents can help the counselee in dealing with similar problems in the future. This is not possible if counseling is done through face-to-face interviews.

Cyber counseling can avoid what is called Conveying Emotions or transfer of emotions from counselee to counselor. For example in face-to-face counseling, a counselee who has certain feelings such as anger or hate toward objects in the past will direct those feelings to the counselor unconsciously so that it can disrupt the counselor's emotions and reduce his professionalism. Richards \& Viganó (2013) explains that this phenomenon is one of the causes of failure in counseling. Cyber counseling can reduce this emotional transfer by not meeting directly between the counselor and counselee in the counseling process. Cyber counseling allows counselees to be more willing to express comfortably personal things that are very difficult to convey if counseling is done face-to-face. Budianto et al. (2019) added that cyber counseling provides a separate room for counselors and counselees so that the counselee feels comfortable expressing personal problems to the counselor, especially cyber counseling takes place by not meeting face to face.

In general, this study also has relevance to the results of other previous studies which found that cyber counseling or online therapy is generally as effective and satisfying as faceto-face counseling (Attridge, 2011; Murphy et al., 2009; Péñate, 2012). Mallen et al. (2005) in the results of their review revealed that online counseling can be a viable service choice for 
several clients especially those who are usually isolated. Richards \& Viganó (2013) added that to date online counseling has the same positive impact as face-to-face counseling and can replicate the facilitative conditions of face-to-face counseling. Budianto et al. (2019) prove that counseling using Whatsapp media is very effective and efficient to assist teachers in conducting counseling. Cyber counseling also makes it easier for counselee parents to participate in monitoring the counselee's progress in the following counseling. However, Wilson et al. (2017) encountered several obstacles in cyber counseling such as the difficulty of counselees choosing problem solving and the difficulty of interpreting emotional expressions from counselees because counselors were not specifically trained in conducting online counseling. The same problem did not occur in this study because both counselors and counselees had been trained in advance to carry out online counseling activities.

Acceptability) and the effectiveness of models and cyber counseling guidelines in this study have been tested empirically. The results of this study have overcome the problem of unavailability of cyber counseling models and guidelines that have been tested empirically through scientific research. The results of this study can be used by guidance and counseling teachers in conducting counseling services in schools. The use of cyber counseling can make counseling activities simpler because it does not depend on distance, place, and time. Of course, this greatly facilitates the process of guidance and counseling service activities.

The cyber counseling model and guidelines need to be integrated with other counseling models to provide more specific guidance and counseling services related to the situation in the field. Self-Adler counseling models, Cognitive Behavior Modification, Reality Counseling, Short Focused Brief Counseling, Humanistic, and Gestalt are some counseling models that are very suitable to be integrated and developed with the cyber counseling model. Therefore, the development of models and guidelines for cyber counseling with various other counseling models is very necessary to do in the future.

\section{Conclusion}

The acceptability of the cyber counseling model and guidelines developed in this study is very high. In addition, cyber counseling models and guidelines are effective as models of counseling services for high school students in the digital age. Based on these findings, guidance and counseling teachers are advised to use cyber counseling as a counseling model to help students achieve independence and solve problems faced because cyber counseling has several advantages when compared to face-to-face counseling. Related research in cyber counseling, other researchers are advised to expand the subject of research.

\section{Acknowledgement}

I thank Prof. Dr. Ni Ketut Suarni, M.S., Kons. and Dr. II Komang Sudharma, M.Pd. as the judges for acceptability models and guidelines of cyber counseling. I also thank the guidance and counseling teachers at Undiksha Laboratory High School as the counselors to carry out cyber counseling, as well as the students as the participants.

\section{References}

Attridge, M. (2011). The emerging role of e-therapy: online services proving to be effective. The Journal of Employee Assistance, 4, 10-13. https://www.thefreelibrary.com/The+emerging+role+of+e- 
therapy\%3A+online+services+proving+to+be...-a0271883307

Bastemur, S., \& Bastemur, E. (2015). Technology based counseling: perspectives of Turkish counselors. 176(1998), 431-438. https://doi.org/10.1016/j.sbspro.2015.01.493

Budianto, A. A. A. E., Aziz, A., \& Nur, H. (2019). ICT application in cyber counseling as a teacher accelerator with optimizing WhatsApp based mobile computing ICT application in cyber counseling as a teacher accelerator with optimizing WhatsApp based mobile computing. Journal of Physics: Conference Series, 1357(1), 01. https://doi.org/10.1088/1742-6596/1375/1/012006

Chaffey, D. (2020). Global social media research summary 2020. Smart Insight. https://www.smartinsights.com/social-media-marketing/social-media-strategy/newglobal-social-media-research/

Dowling, M., \& Rickwood, D. (2016). Exploring hope and expectations in the youth mental health online counselling environment. Computers in Human Behavior, 55, 62-68. https://doi.org/10.1016/j.chb.2015.08.009

Garde, E. L., Point, T., \& Health, E. (2017). Characteristics of clients currently accessing a national online alcohol and drug counselling service. https://doi.org/10.1177/1039856216689623

Geraijasa. (2019). Praktik Ecomersi pada Lingkup Asean Ditinjau dari Hukum Internasional. Geraijasa.Com. https://geraijasa.com/2019/04/27/praktik-e-comerce-pada-lingkupasean-ditinjau-dari-hukum-international/

Gergory, R. J. (2012). Psychological Testing, Hystory, Principle, and Application Sixth Edition. Pearson Education, Inc.

Gregory, R. J. (2012). Psychological Testing, Hystory, Principle, and Application Sixth Edition (6th ed.). Pearson Education, Inc.

Ivey, A. E., Ivey, M. B., \& Zalaquett, C. P. (2012). Essentials of Intentional Interviewing: Counseling in Multicultural World. Brook/Cole Cengage Learning.

Joyce, B. R., Weil, M., \& Calhoun, E. (2000). Models Of Teaching. Pearson Education, Inc.

Lan, C. M. (2016). Predictors of willingness to use cyber counseling for college students with disabilities. Disability and Health Journal, 9(2), 346-352. https://doi.org/10.1016/j.dhjo.2015.11.004

Li,Lau, P., Jaladin, R. A. M., \& Abdullah, H. S. (2013). Understanding the Two Sides of Online Counseling and their Ethical and Legal Ramifications. Procedia - Social and Behavioral Sciences, 103, 1243-1251. https://doi.org/10.1016/j.sbspro.2013.10.453

Maili, T., Dmitri, R., Merle, P., \& D, E. J. (2020). Temporal Patterns of Initial Submissions to Online Counseling When Do People Seek Internet Counseling? Exploring the Temporal Patterns of Initial Submissions to Online Counseling Services. Journal of Technology in Human Services, $0(0), \quad 1-19$. https://doi.org/10.1080/15228835.2018.1561348

Mallen, M. J., Vogel, D. L., Rochlen, A. B., \& Day, S. x. (2005). Online Counseling: Reviewing the Literature From a Counseling Psychology Framework. In The Counseling Psychologist (Vol. 33, Issue 6). https://doi.org/10.1177/0011000005278624

Mishna, F., Bogo, M., \& Sawyer, J. L. (2015). Cyber Counseling: Illuminating Benefits and Challenges. Clinical Social Work Journal, 43(2), 169-178. https://doi.org/10.1007/s10615-013-0470-1

Murphy, L., Parnass, P., Mitchell, D. L., Hallett, R., Cayley, P., \& Seagram, S. (2009). Client satisfaction and outcome comparisons of online and face-to-face counselling methods. British Journal of Social Work, 39(4), 627-640. https://doi.org/10.1093/bjsw/bcp041

Norizan, W., \& Hashim, W. (2013). Development of a usable online counseling management 
system. 97, 761-765. https://doi.org/10.1016/j.sbspro.2013.10.298

Péñate, W. (2012). About the effectiveness of telehealth procedures in psychological treatments. International Journal of Clinical and Health Psychology, 12(3), 475-487.

Prasetiawan, H. (2016). Cyber Counseling Assisted with Facebook Cyber Counseling Assisted With Facebook to Reduce Online Game Addiction. Journal of Guidance and Counseling, 6(1), 28-36. https://doi.org/http://dx.doi.org/10.24127/gdn.v6i1.409

Prasetya, A. D., Sugiyo, \& Japar, M. (2020). Web-based Cyber Counseling to Improve Students' Counseling Interests. Jurnal Bimbingan Konseling, 9(2), 144-150. https://doi.org/https://doi.org/10.15294/jubk.v9i2.32147

Richards, D. (2009). Features and benefits of online counselling: Trinity college online mental health community. British Journal of Guidance and Counselling, 37(3), 231-242. https://doi.org/10.1080/03069880902956975

Richards, D., \& Viganó, N. (2013). Online Counseling: A Narrative and Critical Review of the Literature. Journal of Clinical Psychology, 69(9), 994-1011. https://doi.org/10.1002/jclp.21974

Rida, A. A. (2019). Penerapan Konselor Sebaya dalam Mengoptimalkan Fungsi Layanan Bimbingan Konseling di Sekolah Application of Peer Counselors in Optimizing the Functions of Guidance Counseling Services in Schools. June. https://doi.org/10.24014/jp.v15i1.6549

Salleh, A., Hamzah, R., \& Nordin, N. (2011). From face - To - Face to cyber mode: Life-long learning in counseling for all. Proceedings of the WSEAS/IASME International Conference on Educational Technologies, 124-128.

Sari, A. N. N. (2015). No Title. Prezi.Com. https://prezi.com/f2ckn_78pnkv/cyber-counseling/

Savic, M., Dilkes-frayne, E., Carter, A., Kokanovic, R., Manning, V., Rodda, S. N., \& Lubman, D. I. (2018). Making multiple 'online counsellings' through policy and practice: an evidence-making intervention approach. International Journal of Drug Policy, 53, 73-82. https://doi.org/10.1016/j.drugpo.2017.12.008

Sekretariat Nasional Asean - Indonesia. (2019). Pengguna Internet di ASEAN Diprediksi 7,5 Miliar di 2030. Sekretariat Nasional Asean - Indonesia. http://setnasasean.id/news/read/pengguna-internet-di-asean-diprediksi-7-5-miliar-di2030\#: :text=Riset yang dilakukan Google dan,di antaranya ternyata dari Indonesia.

Setti, S., \& Wanto, A. (2019). Analysis of Backpropagation Algorithm in Predicting the Most Number of Internet Users in the World. 3(2), 110-115. https://doi.org/10.15575/join.

Simone, R., Dan, I. L., Nicki, A. D., Anna, B., \& Alun, C. J. (2013). Web-Based Counseling for Problem Gambling: Exploring Motivations and Recommendations. Journal of Medical Internet Research, 15(5), e99. https://doi.org/10.2196/jmir.2474

Sutijono, S., \& Farid, D. A. M. (2018). Cyber Counseling di Era Generasi Milenial. Sosiohumanika, 11(1), 19-32.

Wilson, S. R., Rodda, S., Lubman, D. I., Manning, V., \& Yap, M. B. H. (2017). How online counselling can support partners of individuals with problem alcohol or other drug use. Journal of Substance Abuse Treatment, 78, 56-62. https://doi.org/10.1016/j.jsat.2017.04.009 